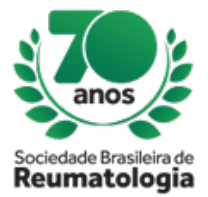

\title{
LUPUS X MULTIPLE SCLEROSIS: A DIAGNOSIS CHALLENGE
}

Thaynara Sarmento Oliveira Almeida (Centro Universitário de João Pessoa, João Pessoa, PB, Brasil), Pablo Duarte de Lima (Centro Universitário de João Pessoa, João Pessoa, PB, Brasil), Teresa Patricia Acebey Crespo (Centro Universitário de João Pessoa, João Pessoa, PB, Brasil), Salomão Nathan Leite

Ramalho (Faculdade de Medicina do Juazeiro, João Pessoa, PB, Brasil), Bianka Martins da Silva Nascimento (Centro Universitário de João Pessoa, João Pessoa, PB, Brasil), Bianca Etelvina Santos de Oliveira (Centro Universitário de João Pessoa, João Pessoa, PB, Brasil), Marina Brasileiro Cesar Leitao (Centro Universitário de João Pessoa , João Pessoa, PB, Brasil), Monique Conceição Martins Alves da Silva (Centro Universitário de João Pessoa, João Pessoa, PB, Brasil)

\section{BACKGROUND}

: Systemic lupus erythematosus (SLE) and multiple sclerosis (MS) are autoimmune diseases of distinct pathophysiologies that affect the central nervous system (CNS) due to their degenerative and demyelinating characteristics, respectively. However, SLE may also affect other systems, such as osteoarticular.

\section{CASE REPORT}

L.R.B., female, 22 years old, reported that in 2005 she presented diffuse petechiae associated with thrombocytopenia, being diagnosed with idiopathic thrombocytopenic purpura (ITP), treated with prednisone and azathioprine. In 2008, she reported headache and pain in the upper members (MMSS) and lower members (MMII), associated with paresthesia and improving with the use of azathioprine. A year later, he returned to the same clinic, but evolved with gait and locomotion disorder. Magnetic resonance imaging (MRI) was performed demonstrating hypersignal focus in T2/FLAIR with demyelinating aspect and liquor with positive Pandy and Nonny reactions, indicating MS, initiating pulse therapy with prednisolone $1 \mathrm{~g}$ for 3 days and recombinant interferon beta-1a $22 \mathrm{mcg}$ daily. In addition, in 2011 and 2019 presented optic neuritis in both eyes, without alterations in retinography, improving with pulse therapy. Thus, in 2012, the neurologist optimized the interferon dose to $44 \mathrm{mcg}$ because of the following complementary exams: HSV $=70, \mathrm{CH} 50=38.8$, Anti-DNA, HLA-B27 and unreacted rheumatoid factor, C3 $=142, C 4=21$, Cardiolipin IgG $=9.4$ and $\operatorname{IgM}=16.6, F A N$ reagent with fine dot pattern $1 / 80, P C R<6.5$ and MRI without significant evolutions. In 2018, she presented painful complaints characteristic of a sacrumileitis, and the rheumatologic evaluation indicated a cascate of prednisone, presenting relief. She returned with hip RNM indicating subchondral edema, computed tomography (CT) of the lombar spine with calcification of the dural sac at the level of $L 5$ and cranium MRI without evolution, besides the following results: anti-cardiolipin IgG (3,7), CD20 ( 28) and total (1608), VHS (37), PCR (<0.1), C3 (85), C4 (9), CH100 (81), CD29 (32\% and $1838 \mathrm{~mm} 3$ ), Aquaporin 4 negative and FAN of fine dot pattern 1/160. Changed to a hypothetical diagnosis for SLE and Iniciated the treatment with metrotexate for joint complaints, reporting remission. Waiting for release of rituximab by the city hall to control the neurological manifestations of the disease.

\section{CONCLUSION}

The exams initially indicated a neurological condition due to MS; however, the purpuric, optic and remissive joint symptoms did not fit. On the contrary, laboratory and imaging alterations in the course of the case indicate a juvenile SLE. 